\title{
Iglesia y Política en Andalucia a finales del siglo XIX. El adoctrinamiento a través de la prensa católica sevillana
}

\author{
JOSE DOMINGUEZ LEON
}

\section{PRECISIONES EN TORNO AL TEMA Y A LA EPOCA.}

Hablar de la situación política en Andalucía a finales del siglo XIX implica tratar sobre la cuestión del caciquismo y de los pilares básicos que lo sustentaban, tanto ideológicos como materiales. En esos momentos se había consolidado en la Iglesia andaluza, y más concretamente en el clero, una corriente de rechazo total a cuanto suponía apertura política $y$, fundamentalmente, igualitarismo, en el sentido que se ejemplificaba en el sufragio universal. Las motivaciones de esta postura son diversas y requieren una particular atención, sobre todo por la aparente confusión que genera la reacción eclesial contra lo que se definía como obra de la revolución y del liberaqlismo para, en el período finisecular, arremeter contra todo lo que significase apoyo u obra del socialismo.

De hecho, en la terminología utilizada por los católicos de la época, se plantea que reinaba en la sociedad una especie de caos como producto del avance de la revolución y de las corrientes racionalistas -entiéndase materialistas- cuya culminación sería el socialismo. Precisamente, durante las décadas de los años setenta a noventa, se suceden serias críticas y condenas hacia las expresiones políticas liberales y socialistas, no debiendo verse en estas actitudes un posicionamiento de carácter local, ni siquiera regional, en el sentido de que los principales medios de adoctrinamiento y propaganda recogen tanto la doctrina pontificia y la de los prelados españoles y europeos como las más significativas manifestaciones de la prensa católica del mundo occidental.. Creo que este es uno de los rasgos más destacados de las publicaciones católicas andaluzas de la época, y más concretamente de las sevillanas, es decir, el rebasar el mero marco local o regional dado que insertaban una gran cantidad de informaciones, artículos y documentación de otras revistas españolas y extranjeras. Esto 
conlleva un alto nivel de interrelación, así como una perspectiva de lo que sería el catolicismo europeo, salvando las naturales diferencias.

El presente trabajo se centra en la principal fuente católica de la prensa sevillana en esta etapa, la heredera de toda una tradición combativa y contrarrevolucionaria como era La Revista Católica, surgida en 1877 por el impulso de Ventura Camacho, hombre muy ligado a los movimientos culturales sevillanos casi desde mediados de siglo, unido a la vida universitaria por haberse hecho cargo de la Biblioteca Provincial y Universitaria. En el fondo, la militancia católica de publicaciones como la citada había recogido la antorcha que transportó la revista $\mathrm{La} \mathrm{Cruz}$ desde que en 1852 fuera fundada por el carlista y catedrático de griego de la Universidad de Sevilla León Carbonero y Sol. La etapa sevillana de La Cruzes fundamental para comprender la línea emprendida por La Revista Católica, aparte de que la redacción de aquella emigró de Sevilla en 1868, con lo cual dejó una especie de vacío que apenas pudo ser rellenado por otras publicaciones a lo largo del Sexenio Revolucionario, ni por periódicos de idéntica inspiración como $\mathrm{El}$ Oriente, debido a la temática extensa y general que trataban y del reducido ámbito local o provincial en que se desenvolvían' ${ }^{1}$.

También es preciso aludir al momento político que se vivía tanto en la Iglesia española como en la europea a finales de siglo debido a los cambios cruciales en materia social. Todo el rechazo eclesial hacia las alternativas políticas liberales y socialistas se había recrudecido a lo largo a los años ochenta y particularmente al inicio de los noventa cuando, recuperado el movimiento obrero europeo tras el desastre sobrevenido por las consecuencias de la Comuna, se gestó la organización de la Segunda Internacional y el socialismo se ofrecía a los trabajadores como la panacea para todos mos males sociopolíticos ${ }^{2}$.

Aunque la actitud de la Iglesia española se había caracterizado por la extensión de la acción social en el sentido más amplio posible, con innegables obras y una decidida tendencia a la orientación y protección del obrero, hay demasiados indicios que nos sugieren un alejamiento progresivo -y a veces agresivo- de las masas trabajadoras con respecto a la Iglesia. El papa León XIII tuvo la sensibilidd suficiente como para

(1) Cfr. BRAOJOS GARRIDO, A. y TORIBIO, M., Guia de la Hemeroteca Municipal, vol. I, $2^{2}$ ed. Ayuntamiento de Sevilla, Sevilla, 1990, y GOMEZ ZARZUELA, V., Guia de Sevilla y su provincia....para 1891, Sevilla, 1891, pp. 222-223.

(2) En este sentido, vid. ANDRES GALLEGO, J., La política religiosa en España. 1889-1913, Editora Nacional, Madrid, 1975; Sobre las formas de pensar y de ser y La Iglesia, en Historia de España y América, vol. XVI-I, Ed. Rialp, Madrid, 1982, pp. 283-382 y 677755. También vid. KRIEGEL, A., La Segunda Internacional (1889-1914), y VILAR, P., $E l$ socialismo español de sus origenes a 1917, en Historia General del Socialismo, vol. II, Ed. Destino, Barcelona, 1979, pp. 560-566 y 317-321. 
superar algunas de las diatribas del catolicismo originas durante los pontificados anteriores, especialmente durante el de Pío IX, cuya condenación de errores contenida en el Syllabus era una pesada carga que impedía en gran medida las actuaciones políticas de los católicos. Si a esto unimos la denominada cuestión romana y la autoconsideración del pontífice como un prisionero en el Vaticano, se puede entender la larga serie de movilizaciones en torno a la adhesión y apoyo hacia el papa, así como que éste culminase su línea condenatoria prohibiendo a los católicos italianos participar en el aparato electoral bajo amenaza de excomunión. El reflejo de estas medidas sobre la mentalidad un tanto extremista de los católicos españoles creo que llevó a una especie de apatía política al no encontrar alternativas claras a las cuales apoyar. Este fue el gran caballo de batalla en el marco de la vida política española, o rechazar las medidas igualitarias porque indirectamente perjudicaban a la Iglesia en un ambiente anticlerical y antirreligioso, o apoyarlas limpiamente y arriesgarse a perder casi todos los privilegios que le quedaban a la Iglesia y, por supuesto, cualquier tipo de favorecedora vinculación con el estado ${ }^{3}$.

El hito más importante de la Iglesia durante 1891 fue la promulgación por León XIII de la encíclica Rerum novarum, que tuvo un enorme impacto en el catolicismo andaluz aunque, como en tantas cuestiones sociopolíticas, el pontífice planteaba una serie de aspectos difícilmente asumibles por la mayoría de los fieles, sobre todo por la gran dosis de responsabilidad que exigían. Existe una relación de causa efecto entre la elaboración definitiva de la encíclica -que llevaba varios años gestándosey el avance aparentemente arrollador del socialismo pues la formación de la Segunda Internacional precipitaría la puesta a punto de la doctrina social de la Iglesia. El Congreso Católico Nacional celebrado en Sevilla en 1892 tuvo una indudable repercusión en el terreno de lo social y de lo político, a juzgar por el contenido de las conferencias y comunicaciones presentadas, si bien la propia dinámica de las sesiones impedía un tratamiento a fondo de cuestiones estrictamente políticas al estar demasiado controlada la discusión. Esta era una prueba clara de la línea escasamente intervencionista de los católicos en la política, habida cuenta de los derroteros igualitaristas que tomaba con la ampliación del sufragio masculino ${ }^{4}$.

(3) Cfr. ANDRES GALlEgo, J., Pensamiento y acción social de la Iglesia en España, Ed. Espasa-Calpe, Madrid, 1984. También vid. Syllabus, en GUTIERREZ GARCIA, J. L., Doctrina Pontificia. II. Documentos políticos, B.A.C., Madrid, 1958, pp. 19-38.

(4) Vid. DOMINGUEZ LEON, J., La doctrina social católica en Andalucía Occidental a finales del siglo XIX y el impacto de la Rerum novarum. El caso sevillano, en Las Fiestas de Sevilla en el siglo XV. Otros estudios, C.E.I.R.A. II, Ed. Deimos, Madrid, 1991, pp. 207232, y La Rerum novarum y su impacto_en España. El Congreso Católico de Sevilla de 1892 y la cuestión social, en Doctrina social de la Iglesia y realidad socio-económica. En el centenario de la <<Rerum novarum $>>$, EUNSA, Pamplona, 1991, pp. 159-171. 
La crisis finisecular se produciría antes de 1898 en ciertas estructuras, afectando fuertemente al catolicismo que pasaba por una honda depresión, arrastrada desde la etapa de los grandes cambios sociales e institucionales que comenzó con la quiebra del Antiguo Régimen. Se trataba, en suma, de resolver enormes contradicciones producidas por el acomodo a nuevas situaciones en las cuales ya no era posible mantener a la Iglesia a la sombra del estado. Las connotaciones de este posible desequilibrio podrían estar definidas por un desenfoque pastoral y de apreciación en cuanto a la realidad social, y un excesivo mecanicismo y esquematismo en el cumplimiento de los dictados de la jerarquía. Puede que el fondo de la cuestión radicase en la apreciable falta de pensadores católicos que pusieran el dedo en la llaga sobre los más acuciantes problemas sociales y políticos.

Estaba claro el adoctrinamiento político por parte de la jerarquía aclesiástica cuando a comienzos de 1891, ante las elecciones que debían celebrarse el 1 de febrero, los prelados españoles aleccionaron insistentemente a los católicos para que no votasen a ningún diputado liberal, con lo que dejaron a buen número de fieles en la más absoluta de las indecisiones, máxime cuando el obispo de Plasencia incluía en las filas del liberalismo a republicanos y monárquicos liberales y conservadores. Se recurrió a la condenación de errores efectuada en el Syllabus hasta el punto de situar a los electores católicos practicantes en una coyuntura de ambigüedad y contradicción: o se votaba a un gran partido -por ejemplo, el conservador- que fuese capaz de llevar a cabo una política de mayorías a escala nacional y se incurría en una pecaminosa falta, o se votaba a pequeñas alternativas locales o provinciales sin la menor garantía de que se sentaran en el parlamento o de hacerlo de manera coherente. Desde luego, existía otra posibilidad bastante clara incluso para los menos inteligentes: quedarse sin votar y engrosar el lamentable grupo de abstencionistas en un país que precisaba de participación política de cara a la estabilidad, actitud que en casi nada se diferenciaría de las puramente nihilistass.

\section{EL TRATAMIENTO DE LA CUESTION POLITICA EN LA PRENSA CATOLICA Y EN LAS PUBLICACIONES ADOCTRINADORAS.}

A lo largo de la segunda mitad del siglo XIX se fueron prodigando en España las publicaciones de tipo adoctrinador a modo de catecismos de la más variada naturaleza, así como una cantidad bastante respetable de pequeños tratados de religión o de doctrina cristiana que no eran sino

(5) Cfr. La Revista Católica (en lo sucesivo L.R.C.), 25-I-1891, -La Iglesia y las elecciones políticas. 
versiones reducidas de la Teología dispuestas para ser entendidas por la mayoría. Casi todas estas publicaciones tenían un carácter eminentemente didáctico, no sólo por su forma de exponer la doctrina, a base de preguntas y respuestas, o englobando grandes áreas temáticas en determinados capítulos, sino porque muchas de ellas fueron concebidas para ser empleadas como libros de texto en la segunda enseñanza o en las Escuelas Normales, con lo cual se aseguraba su proyección a través de la práctica educativa.

Las versiones catequéticas que más se difundieron eran modificaciones y puestas al día de los catecismos de Ripalda y Astete, con manifiestas mejoras como el de García Mazo, o específicos en un capítulo concreto como el del cardenal García Cuesta para uso del pueblo contra el protestantismo. Todo esto ocurría en unas décadas durante las cuales se habían consolidado grandes librerías y editoriales de tipo religioso, que efectuaban cuantiosas tiradas y abarataban el libro y cualquier otro tipo de publicaciones. Un ejemplo muy claro en este sentido fue la Libreria Religiosa de Barcelona, que tuvo enorme influencia sobre el terreno de la difusiốn de la cultura religiosa católica en la España de la segunda mitad del siglo XIX. El papel de los medios de comunicación de cara al adoctrinamiento se vio notablemente reforzado en esta etapa gracias a la consolidación de los boletines eclesiásticos de los distintos a rzobispados y diócesis, a lo que se unían las publicaciones propias de diversas asociaciones y entidades de carácter religioso, conformando entre todos lo que era denominado buena prensd $d^{6}$.

No obstante, creo que la difusión de este tipo de publicaciones ha de ser estudiada con detenimiento puesto que apenas tendría incidencia entre los sectores más humildes, analfabetos en su mayoría. De acuerdo con los datos del censo de 1877 , había en la capital sevillana un $54{ }^{\prime} 72$ por ciento de analfabetos totales, cantidad que debía ser más alta, ya que se solía incluir entre los que sabían leer y escribir a quienes sólo sabían firmar. Este índice de incultura se elevaba en la provincia, arrojando el mismo censo un 73 por ciento de analfabetos. Las escuelas públicas y privadas parece que poco podían hacer para disminuir sensiblemente este alarmante indicativo, en primer lugar porque eran claramente insuficientes, y en segundo porque nada obligaba a la escolarización forzosa de la población infantil, y esta se dedicaba desde muy temprana edad a trabajar en ocupaciones lucrativas. Sin embargo no se debe olvidar el esfuerzo realizado por algunas instituciones de carácter religioso en pro de la escolarización y enseñanza de las primeras letras, especialmente en

(6) Vid. JIMENEZ DUQUE, B., Espiritualidad y apostolado, en La Iglesia en la España contemporánea (1808-1975), B.A.C., Madrid, 1979, pp. 446-447. 
capitales como Sevilla, donde numerosas congregaciones religiosas instalaron colegios e incluso se dedicaron a la enseñanza de adultos mediante clases nocturnas y dominicales?

En el apartado correspondiente a los métodos hay que hacer hincapié en una evidente contradicción entre lo renovado de los mismos y lo anticuado de sus contenidos. Se trataba, llanamente, de que con todo el aluvión de publicaciones y la popularización de las instituciones educativas católicas no se superaba el lenguaje empleado, casi siempre condenatorio y escasamente constructivo, de manera que recordaba los anatemas continuamente lanzados por la jerarquía. La renovación en las cuestiones estrictamente didácticas en el ámbito de la catequesis infantil vinieron en Andalucía de la mano del padre Manjón, en el área granadina, y del obispo Manuel González, primero en Huelva como arcipreste y más tarde en Málaga como prelado, aunque ya en el primer tercio del actual siglo ${ }^{8}$.

Durante la coyuntura el Sexenio Revolucionario, y después del traslado de la redacción de $\mathrm{La} C \mathrm{Cr} z$, apareció en Sevilla la que sería la gran revista católica andaluza, que bajo la dirección de Ventura Camacho se publicó con el nombre de La Semana Católica entre enero de 1873 y junio de 1877, pasando entonces a titularse La Revista Católica ${ }^{9}$. La revista mostró una vitalidad asombrosa pues se publicó hasta finales de 1898, quizás debido al celo y al impulso de su director y al faltar este se vino abajo.

De acuerdo con los índices de analfabetismo apuntados y teniendo presente la pobre inclinación hacia la lectura de la mayoría de los fieles, resulta claro que la revista, al igual que las demás de su clase, sólo tendría ura difusión reducida entre los círculos clericales y entre los seglares más comprometidos, aunque no exclusivamente en la diócesis sevillana a pesar de que en sus inicios estuvo auspiciada por el arzobispado hispalense, sino que tenía una proyección similar a otras en un ámbito nacional. El hecho de que editase casi todos los documentos pontificios de cierta importancia, al igual que los de los más destacados prelados y artículos y reseñas de otras revistas españolas y extranjeras, la hacía suficientemente atractiva para estar al día acerca de las cuestiones más candentes del catolicismo. Paralelamente, se puede hablar de un núcleo propagandista sevillano constituido por las revistas reseñadas y por la actividad publicista de algunos prelados de la diócesis que, como fray Zeferino González, elevaron notablemente el tono teórico del catolicismo militante andaluz ${ }^{10}$.

(7) Vid. GOMEZ ZARZUELA, V., Guia ... para 1886, p. 112 y Guia ... para 1890, pp. 191192 y $194-197$.

(8) Cfr. JIMENEZ DUQUE, B., op. cit., p. 447.

(9) Vid. BRAOJOS GARRIDO, A. y TORIBIO, M., op. cit.

(10) Vid. JIMENEZ DUQUE, B., op. cit., pp. $433-434$ y en un sentido meramente divulgativo ROS, C., Los Arzobispos de Sevilla, Sevilla, 1986, pp. 254-273. 
Los receptores de la revista y de otras publicaciones similares actuarían a modo de propagadores, reorientando los dictados de la misma a las condiciones concretas de cada situación pastoral. El lenguaje empleado y la densidad de algunos artículos y documentos nos sugiere que la publicación estaba concebida única y exclusivamente en esta dirección aunque, en esta generalidad, sobresale el marcado tono antiliberal y antisocialista que le definía, especialmente cuando al final de los años ochenta y durante los noventa parecía el socialismo una realidad imparable. Este proceso de crítica extrema hacia la vida política europea en su trasfondo más ideológico se fue agudizando a medida que la jerarquía cerraba sus filas en torno a la condenación papal de cuanto sonase a revolucionario o.liberador pues, a excepción de algunos prelados y sacerdotes que trataron el problema social con seria responsabilidad, la mayoría obviaba el abordar dichos temas y cuando lo hacía era para repetir esquemas anatemizantes. Insisto en que este fenómeno es general y no sólo atribuible a las publicaciones católicas andaluzas de la época.

Este mismo proceso se puede seguir a través de otras publicaciones adoctrinadoras influidas por el ambiente descrito. Se trata de catecismos y pequeños tratados de religión con fines escolares que, poco a poco, empiezan a tratar el tema de la vida política y delimitan cuál debería ser la actitud de los católicos en dicho campo. Estas obras pasan por momentos en que apenas se tiene presente la política en el adoctrinamiento, luego cabe pensar que no era una cuestión fúndamental o que se creía tan controlado y propicio el aparato político que no era preciso orientar sobre el mismo. Sin embargo, hacia finales de siglo se introducen capítulos en estas obras referentes a la vida política, en un tono ciertamente despectivo y condenatorio, hasta el punto de que se rechaza totalmente la línea imperante de separar la Iglesia del estado y se sigue planteando la teoría del origen divino del poder, aparte de negar con rotundidad cuanto se acercase al democratismo del sufragio universal y condenando la soberanía popular.

En síntesis, se puede hablar de un endurecimiento en la consideración de la actividad política, constatándose incluso una ausencia del debido reconocimiento de la misma como un servicio a las comunidades, es decir, de su verdadero sentido cristiano.

Otras revistas católicas sevillanas hallaron un camino abonado y se especializaron en áreas concretas, con lo cual su objetivo era mucho más certero. Así, tuvo una buena aceptación la revista Sevilla Mariana como publicación quincenal, especialmente durante los años de 1881 a 1884, aunque siguó editándose, por lo menos, hasta 1886. Pero lo que fue una verdadera aportación sevillana a la difusión de las ideas socialcatólicas y por lo tanto políticas, cristalizó en la publicación de la revista decenal la 
Religión y el Socialismo, dirigida por el sacerdote Juan Bautista Solís, cuyo primer número vio la luz el 10 de enero de 1892, sin lugar a dudas amparado en el ambiente generado por la promulgación de la Rerum novarum. La revista fue anunciada por el Boletín Eclesiástico del Arzobispado recomendando su lectura. Se publicaba apoyándose en que

-[...] La necesidad de publicar Revistas y periódicos que tengan por objeto la propagación de sanas doctrinas que contraríen la corriente de las ideas socialistas, se viene sintiendo por todos los hombres llamados a dirigir el gobierno de los pueblos. Es tan imponente la propaganda de estas ideas, que forman ya una amenaza constante a la tranquilidad de casi todas las naciones: porque así como cada individuo tiene su carácter y fisonomía particular, los siglos también la tienen: el nuestro es característicamente socialista [...].

El resultado era nefasto puesto que ello ocasionaría revoluciones y crisis sociales, destruyendo la moral religiosa, ante lo cual era objetivo de la revista

.[... armonizar estas divisiones, haciendo ver, que ni el pobre es tan desgraciado como se exagera, ni el rico tan feliz como se supone; que la Providencia lo tiene todo nivelado y que en esta miserable vida, no hay ni puede haber desgracia alguna absoluta, ni felicidad perfecta; y que todos los sistemas inventados por el genio humano son insuficientes para calmar la ansiedad de felicidad social, que por todas partes se pide y reclama [...].

La declaración previa de las intenciones editoriales de la revista ahondaba en la condenación del racionalismo moderno, de las ideologías y de la práctica política y lo que es más contradictorio, reconociendo y respaldando situaciones claramente injustas y por añadidura consagrando las desigualdades puesto que no se planteaba criticarlas ni combatirlas ${ }^{11}$.

Ya desde el primer número de La Religión y el Socialismo establecía su director lo que consideraba eran las líneas fundamentales del socialismo, el origen de la propiedad privada -aparece como propiedad individual- y sus conexiones con la caridad. El discurso es equívoco y farragoso, dando probablemente origen a múltiples confusiones entre los lectores. No parece que hubiese una argumentación contundente y definitiva contra el socialismo puesto que no se encuentran referencias expresas al mismo centrado en el movimiento obrero del momento ni al político y, sin embargo, hay continuas alusiones al supuesto pensamiento socialista de los siglos anteriores. Pienso que esta actitud no se puede considerar fruto de una ligereza editorial sino que denota una desmesurada ignorancia de los móviles que estaban orientando la vida socioeconómica y

(11) Cfr. Boletin Oficial Eclesiästico del Arzobispado de Sevilla, 16-I-1892 y La Religión y el Socialismo (en lo sucesivo L.R.Y.E.S.), 10-I-1892, pp. 3-9. 
política en casi toda la Europa occidental, a la vez que se procuraba tomar como modelo de referencia el ya desfasado pensamiento católico español acerca de la materia ${ }^{12}$.

El punto de partida de la revista consistía en la reiterada condena del socialismo y en el sostenimiento de una larguísima serie de ambigüedades que apenas ponían orden ni concierto en la enmarañana polémica social. La cuestión social se entendía como un problema ejemplificado en la lucha entre pobres y ricos, que era necesario superar intentando algunas mejoras, recurriendo a la caridad y contemplando como insuficiente la formación de comisiones de reformas sociales, los jurados mixtos, las cajas de socorros, la limitación de la jornada laboral y el cumplimiento del descanso dominical, señalando que

‘...] fomentar entre las clases proletarias los elementos de mejoramiento material [...] el problema social no consiste realmente en que unos gocen de grandes riquezas mientras otros carezcan en absoluto de ellas y hasta de lo necesario [...] siempre ha de haber pobres y ricos, y hacer todo lo posible por aproximar los unos a los otros, llevándolos a un punto donde sus tendencias se armonicen. Hay que oponer a la predicación disolvente de derechos absurdos, la enseñanza de deberes cumplidos; hay que hacer comprender al rico que el mejor empleo que puede dar a sus riquezas es socorrer las necesidades del pobre, y a este, que no estriba la felicidad en la posesión de los bienes terrenales; hay, en una palabra, que MORALIZAR a unos y otros, y como fuente única de verdadera moralidad es el Catolicismo, hay que difundir la enseñanza católica tan abandonada por desgracia en nuestros días [...] ${ }^{13}$.

La enseñanza a que se refiere la revista estaría conectada con los tratados de moral y doctrina cristiana a los que antes he aludido. Recurriendo a los textos utilizados más comúnmente en las Escuelas Normales andaluzas de la época no encuentro referencias expresas a la cuestión política, tal vez porque fueron redactados varios años antes, algunos incluso décadas, en una coyuntura en que aún se veía muy poco probable el ascenso de la gente poco importante a la palestra política. Este hecho es muy significativo puesto que en la coyuntura estrictamente finisecular aparece un continuo y sistemático tratamiento de la cuestión política como aspecto de primer orden en las publicaciones religiosas que atendían a la formación de la juventud. Así, el Compendio de la doctrina cristiana de José Rodrigo de la Cerda, aprobado como texto para las Escuelas Normales en 1880 , se inscribe en la primera dinámica descrita, por su ausencia de alusiones al entramado político. Su autor reconocía en el prólogo de la

(12) Cfr. L.R.Y.E.S., 10-I-1892, pp. 10-18, El socialismo. Origen de la propiedad individual.

(13) Cfr. ibidem, 31-I-1892, pp. 57-62, *Dos palabras sobre el problema social;y el socialismo. 
obra que se había basado en el catecismo de Mazo para sus explicaciones en clase, de donde había surgido el proyecto para realizar el libro y del que tomó las principales ideas, aunque consultando los Pouget, Gaume y Claret, y de Balmes la obra La Religión al alcance de los niños. El libro parece que tuvo una gran aceptación en las Escuelas de Maestros y Maestras y, con seguridad, llegaría a Sevilla y se difundiría por gran parte de Andalucía al estar editado en Badajoz ${ }^{14}$.

Otro claro ejemplo en la misma dirección lo constituyó la obra de Manuel Encinas y del Soto Breve exposición de la doctrina cristiana...., escrita en los años sesenta y que tuvo numerosas ediciones hasta bien entrado el presente siglo. Igualmente servía de texto en las Escuelas Normales, o al menos con esa finalidad fue concebido, aunque terminó imponiéndose como texto adaptado a la segunda enseñanza. A pesar de sus varias ediciones y de su versatilidad como texto, así como de las numerosas correcciones que ello implicaría sobre el original de 1867 , no se constatan en él alusiones claras al adoctrinamiento político, cuando ya, al comienzo de la actual centuria, esto era una práctica común ${ }^{15}$.

En la orilla opuesta se sitúan obras didácticas mucho más densas en su contenido y más profundas en su concepción, pero que a la hora de abordar el adoctrinamiento político incurren en numerosas condenaciones del sistema liberal. Así, las Lecciones razonadas de Religión y Moral...., de Joaquín Gou Solá, elaboradas de cara a la juventud, condenan desde la incautación de los bienes de la Iglesia y el derecho moderno hasta la consideración de la máxima libertad política indicando que

-[...] La libertad de conciencia puede definirse [como] el pretendido derecho de pensar y obrar como a cada uno le plazca en materia religiosa [...] La libertad de cultos es el pretendido derecho de honrar a Dios con cualquier profesión religiosa [...] Por la libertad de asociación se concede la de reunirse para maltratar a Dios y a su Iglesia, y para atentar contra las instituciones políticas. Es decir: la ley de asociación no habla tan claro; pero los hechos sabidos, tolerados y aún autorizados ponen de manifiesto que contra los dos primeros puede el orador, o lo que sea, despacharse a su capricho, y también contra las segundas, mientras sea algo comedido. Con lo cual basta y sobra para demostrar lo absurdo e irritante de ese derecho. Y no está aquí todo: los mismos que enaltecen la libertad

(14) Sobre el concepto de -gente poco importante, vid. ANDRES GALLEGO, J., Historia general de la gente poco importante. América y Europa hacia 1789, Ed. Gredos, Madrid, 1991. Cfr. RODRIGO DE L.A CERDA, J., Compendio de la doctrina cristiana, Tip. y Enc. de Uceda Hnos., Badajoz, $1888,7^{\mathbf{2}}$ ed..

(15) Vid. ENCINAS Y DEL SOTO, M., Breve exposición de la doctrina cristiana.Con arreglo al programa de esta asignatura y a la uiltima reforma de la $2^{\circ}$ enseñanza, Lib. de los sucesores de Badal, Valencia, 1904, $5^{2}$ ed. 
de asociación (para minar los fundamentos sociales), niéganla con mayor o menor fuerza a las órdenes religiosas, cuya existencia es para muchos padrón de ignominia [...] ¿Y qué decir de la libertad de enseñanza, sino que es el derecho absurdo de envenenar las inteligencias y los corazones desde la cátedra? [...] ${ }^{16}$.

En la misma dirección pero mucho más extremista se sitúan algunos textos que hacen serias incursiones en el mundo de la política para desprestigiar la totalidad de los sistemas imperantes. Un ejemplo notable en este sentido es La entrada en el mundo o guía práctica de la juventud cristiana, publicado por el Apostolado de la Prensa, que dedicaba abundantes apartados concretos en este terreno. Aparte de condenar el racionalismo, las sectas y los sectarios, el protestantismo y a los denominados malos católicos, tildados así por no defender a ultranza los principios de la Iglesia, trata de la política con unos tintes totalmente despectivos

[...] En todos tiempos, hijos míos, pero nunca tanto como en estos últimos, sobre todo de un siglo a esta parte, ha sido la política una grande encubridora de perversidades, y auxiliar complaciente de crímenes y de preocupaciones [...]

Contra la unidad de la fe, suele la política oponer la indiferencia entre todas las religiones, y la libertad de todos los cultos. Contra la caridad activa y consoladora de los cristianos, suele oponer la filantropía helada e infecunda de filosofastros sin alma. Contra la regla segura de la conciencia, suele oponer el ciego estímulo del interés. Contra el espíritu de mortificación regeneradora, suele oponer los desenfrenos de la sensualidad corrosiva.

Por último, contra la fundamental constitución y natural organismo dados por el mismo Dios a las sociedades humanas, suele la política oponer miserables combinaciones de mecanismos, inútiles unas veces, $\mathrm{y}$ otras veces contrarios a la naturaleza eterna del hombre, y a las condiciones esenciales de todas las sociedades humanas [...]. ${ }^{17}$.

Se intentaba argumentar a favor de los principios católicos para que gobiernos y sociedades alcanzasen la paz, la libertad, la justicia y la abundancia, irdependientemente del sistema político de que se dotasen. Esta indefinición política es tanto más grave a finales del pasado siglo cuanto que se subrayaba daba igual un rey absoluto o uno constitucional, o un parlamento más o menos democrático. La cuestión consisía en

(16) Vid. GOU SOLA, J., Lecciones razonadas de Religión y Moral, antídoto contra los principales errores religiosos, antiguos y modernos, que ofrece a la juventud española el Presbitero D. ..., Imp. y Lib. de Paciano Torres, Gerona, 1899, $3^{2}$ ed., pp. 489-491.

(17) Vid. La entrada en el mundo o guía práctica de la juventud cristiana, Admón. del Apostolado de la Prensa, Madrid, 1898, nueva ed. corregida y aumentada, pp. 200-203. 
resolver si los actos e instituciones políticos tenían por norma las enseñanzas de la Iglesia

‘[...] ¡Ah, hijos míos! La política que se divorcia de la Religión, y mucho más la que la hostiliza y la persigue, me asombra menos por lo que tiene de sacrílega, que por lo que tiene de absurda. ¡Insensatos! Si expulsais a Dios del gobierno de las sociedades humanas, ¿qué os queda sino el hombre?. [...] En vano inventais cada día un nuevo mecanismo político que os garantice de la arbitrariedad de los gobernantes y de la rebelión de los gobernados. En vano os agitais, cambiando a cada instante las formas de gobierno, derribando hoy los ídolos que adorasteis ayer, derribando mañana los que hoy adorais. En vano todo: habeis olvidado que el temor de Dios es el principio único de la justa potestad y de la libre obediencia [...]* ${ }^{18}$.

Algunas obras se muestran más recatadas pues sus autores prefieren abordar el tema de la política indirectamente, a través de la moral social, la actitud ante la enseñanza o el trabajo, etc.. En definitiva, eran visiones menos apocalípticas sobre la realidad social y se erigían en obras con valores positivos y universales que contrastaban con la generalidad de las producciones elaboradas en España. Un ejemplo nítido de esta corriente pudo ser en su día la obra La educación cristiana de la juventud, del canónigo de Quito Cornelio Crespo Toral, publicada por Herder en Alemania en lengua castellana ${ }^{19}$.

La inculcación de valores cristianos de cara a la actuación en política había tocado fondo puesto que no se admitían términos medios en los cuales no fuera la religión, y mucho menos la Iglesia, la inspiradora de los principios sociopolíticos, dejando a los católicos en la más absoluta de las indefiniciones y forzándoles a una participación política excesivamente mediatizada. De estas generalidades bebieron las publicaciones adoctrinadoras andaluzas y en concreto las sevillanas, como hemos visto. Tśmbién La Revista Católica adolecería de idénticas debilidades.

\section{LOS PRINCIPAIES CONTENIDOS DE ADOCTRINAMIENTO POLITICO EN *LA REVISTA CATOLICA*.}

Resulta extremadamente complejo escudriñar la explicitación de los contenidos adoctrinadores en lo político de La Revista Católica, ante lo cual es indispensable plantearse una seria reflexión acerca de las características definidoras de los mismos. En primer lugar, es difícil hallar una

(18) Vid. ibidem, pp. 208-209.

(19) Vid. CRESPO TORAL, C., La educación cristiana de la juventud, B. Herder, LibreroEditor Pontificio, Friburgo de Brisgovia (Alemania), 1905, $2^{\text {a }}$ ed.. 
concreción de tales contenidos de una forma clara y rotunda, debido a diversos motivos de índole política y, especialmente, estratégica. La cuestión es simple si tenemos en consideración que la Iglesia había pasado por unas vicisitudes que calificaba de auténtica persecución, pero esto no podía hacerlo abierta y públicamente porque corría el riesgo de hacerse todavía más molesta para los poderes públicos -de los cuales dependía, al menos en lo económico- e impopular de cara a los sectores más amplios de la sociedad. De esta suerte, las quejas y las críticas al sistema político tenían que hacerse de manera velada y casi siempre desde plataformas asociativas o editoriales de carácter laico. En esta dinámica podemos encuadrar la combativa actitud de La Revista Católica y de otros órganos similares.

En segundo lugar, y esto lo formulo como una hipótesis que vengo estudiando y que es preciso verificar, el catolicismo español de finales del pasado siglo estaba atravesando un momento de franca debilidad en cuanto a la solidez de sus pilares teóricos, habida cuenta de la notable falta de intelectuales de conocimiento profundo. Esta generalización hay que concretarla, en este caso, a la ignorancia que denotan los columnistas de este tipo de publicaciones sobre los aspectos político-ideológicos más elementales, de forma que su lenguaje -a veces pura palabrería- ni siquiera llega a rozar la médula de las cuestiones fundamentales que intentan analizar. Asombra en ocasiones la tremenda vaciedad o la visceralidad y la beligerancia en sus concepciones, lo que contrasta con la escasísima capacidad de argumentación. Esta línea no creo que tuviera mucho que ver con el anhelado populismo que pretendian perseguir estas publicaciones en cuanto a captación de lectores porque lo más probable sería que no alcanzasen más allá de los estratos medios de la sociedad.

En tercer lugar, el carácter de publicaciones demasiado apegadas a la coyuntura política provocaría una especie de autocensura sobre los rasgos básicos de la propia política nacional, insertando, sin embargo, gran cantidad de documentos relativos a la situación política europea, y más concretamente italiana. El reflejo de lo estrictamente español encuentra poco eco en sus columnas aunque este mismo hecho permite una apreciación de la realidad occidental por el tamiz de tales publicaciones.

Las grandes áreas a las que se dedicó, en el tratamiento de lo político, La Revista Católica, se pueden dividir en cuatro apartados generales, si bien se podría restructurar tal compartimentación en función de aspectos muy particulares que obedecerían a la propia coyunturalidad que la revista ofrecía a sus lectores. El primer apartado corresponde a los llamamientos y dictados de la jerarquía de la diócesis y de la provincia eclesiástica, poco claros por lo común. El segundo se refiere a la definición de la política en términos generales y la fijación de la Iglesia y del 
catolicismo como únicas alternativas válidas para erradicar los males sociales y políticos que aquejaban a la humanidad. El tercero conecta con la cuestión social, de donde hay que entresacar su trasfondo político, sobre todo por la continua condena a diferentes sistemas y, particularmente, al socialismo. Finalmente, se intenta fijar lo que debería ser el credo político de los católicos y se aprovechan determinadas oportunidades idóneas para el adoctrinamiento.

\section{1. Los llamamientos de los prelados de la diócesis sevillana y de su provincia eclesiástica.}

Desde los comienzos de la edición de la revista existió una preocupación en su director por recoger lo más fielmente posible todo documento importante para la vida de la diócesis, fundamentalmente las pastorales de sus prelados, así como los sufragáneos. El cardenal arzobispo de Sevilla Joaquín Lluch y Garriga promulgó el 7 de octubre de 1877 una carta pastoral en la cual, con motivo de su entrada en la diócesis, daba un repaso a todo lo que consideraba elemental de cara a un fortalecimiento de la vida espiritual, sin olvidar alusiones al momento político y a la importancia que tenía el que los fieles apoyasen a su clero, aunque no se atrevió a elevar acusaciones al estado. Su mensaje se centraba en que

^[...] Las críticas circunstancias en que se halla nuestra pobre y corrompida sociedad, exigen un esfuerzo supremo por parte de los buenos cristianos, cualquiera que sea la clase o condición a que pertenezcan, a fin de remediar los males que le aquejan. El laicato católico es en los tiempos actuales un poderoso auxiliar de los ministros de la religión [...]* ${ }^{20}$.

El mismo cardenal Lluch promulgaba otra pastoral meses después, el 6 de marzo de 1878, con motivo de la cuaresma, en la que, aparte de las naturales consideraciones piadosas, hacía un recorrido por lo que comprendía eran los resultados de la mala prensa en sentido adoctrinador pues, aunque se refería a rasgos no estrictamente políticos, traducía el efecto moral y social de la misma al indicar que

‘[...] Una de las más grandes calamidades que lamentamos en nuestros tiempos es ese aluvión de libros, folletos, revistas y periódicos dictados por el espíritu del mal, y que sus agentes no se cansan de propagar, valiéndose al efecto de todos los medios que su refinada malicia les sugiere, y con éxito que asombra. Miles de impresos inmorales e impíos vomita en cada hora del día la prensa irreligiosa y libertina: pocos son, en comparación de los aludidos, los que salen de las imprentas católicas. Todos son obstácu-

(20) Cfr. L.R.C., 2, 8 y 16 XII-1877. 
los, escasez y pobreza, cuando se trata de favorecer y difundir las publicaciones que contienen sanas doctrinas y de verdadera ilustración [...].

Continuaba abundando en lo pernicioso de la prensa diaria, revistas y libros, que inundaban desde las casas más altas a las más humildes, pasando por los casinos, tabernas y lugares de recreo ${ }^{21}$.

A los pocos meses insertaba la revista una exposición a las cortes que habían elaborado los prelados de la provincia eclesiástica el 8 de julio del año anterior, a propósito del proyecto de ley de instrucción pública. Interrogaban sobre si la Religión y la moral católica eran consideradas simplemente con el rango de asignaturas -lo cual era hasta mezquino para ellos- 0 , si por el contrario, eran fundamentales y debían someterse a ellas todos los profesores y alumnos en todas las materias que se cursaran

‘...] Si por el contrario se entiende en el segundo, como es natural suceda, atendidas las condiciones de nuestro pueblo español y de sus legisladores, católicos deben ser los profesores, católicas las doctrinas que se inoculen en el ánimo de los alumnos, católico el espíritu de la enseñanza general y particular [...]. ${ }^{22}$.

Bastante más lejos llegaba en sus apreciaciones el cardenal fray Zeferino González cuando en 1886 inauguraba su segundo pontificado en la sede hispalense. Discurría en su pastoral sobre el sentido profundo de la libertad que preconizaba el racionalismo y que era empleada contra la Iglesia como un arma arrojadiza. Centraba su mensaje en la defensa del Sumo Pontífice a la vez que perfilaba el papel de la Iglesia en la cuestión romana y hacía un claro llamamiento a todos los fieles de la diócesis para que apoyaran incondicionalmente al papa. El fondo radicaba en el establecimiento de una línea nítida en el asunto de las relaciones Iglesia-estado, aunque por la dificultad extrema en el planteamiento del tema no llegó el prelado a pedir ningún tipo especial de movilización inmediata. Es indudable que su talante abierto le llevó a tomar posiciones más sólidas en el futuro, pero tres años después renunció a la sede sevillana debido a una grave dolencia que años más tarde le provocaría la muerte ${ }^{23}$.

Todavía en 1897 replanteaban los prelados de la provincia eclesiástica el crudo asunto de la ortodoxia católica en el terreno de la enseñanza, refiriéndose a los catedráticos y a los programas como no sujetos al dogma, a pesar de que -argumentaban los obispos- la Iglesia había mostrado siempre un gran respeto por la libertad científica, mantenido con creces hasta en los momentos de más intolerancia. Entre los síntomas de cambios

(21) Cfr. ibidem, 10-III-1878.

(22) Cfr. ibidem, 2-VI-1878.

(23) Cfr. ibidem, 6-VII-1886 y ROS, C., op. cit., pp. 258-264. 
políticos reiteraban sus críticas al matrimonio civil y exigían a los jueces que no celebrasen ninguno entre personas que se declarasen católicas ${ }^{24}$.

\section{2. La política y la Iglesia como única alternativa.}

Tanto La Revista Católica como otras publicaciones de tintes parecidos se habían esforzado en editar cuantos documentos pusieran de relieve el presunto peligro en que se encontraban los católicos en cuanto a las lecturas. Una parte primordial del adoctrinamiento político consistió en la larga serie de prohibiciones que se dictaron, desde la Santa Sede a los obispos, acerca de determinadas lecturas. Debemos tener presente que a lo largo de toda la segunda mitad del siglo XIX se fue gestando y consolidando una vasta teoría política en relación a la libertad de imprenta, que encontró siempre un belicoso enemigo en la Iglesia. Bautista Lázaro e Izquierdo recordaba en la revista que las prohibiciones estaban en ristre y que la Iglesia había condenado el moderno derecho de aquellos tiempos denominado libertad de imprenta, haciendo referencia al Syllabus y al anexo de condenación de errores de la encíclica Quanta cura. La propuesta estaba formulada en términos de impedir el progreso de alternativas ideológicas y políticas no conformes con el catolicismo ${ }^{25}$.

El mismo publicista hacía hincapié en la oleada de propaganda antirreligiosa que inundaba la sociedad. Describía una Sevilla en la que, como fruto de la revolución -término ambiguo utilizado masivamente por este tipo de prensa- imperante, habían proliferado la blasfemia, la literatura malévola, las obscenidades tabernarias y hasta el lenguaje más soez en el seno de las familias cristianas ${ }^{26}$.

La vaguedad terminológica del vocablo revolución alcanzaba extremos insospechados. La revolución era directamente responsable de todos los males que se cernían sobre la Iglesia, y por añadidura se empleaba a modo de comodín cuando se carecía de argumentaciones serias. Se le emparentaba con el diablo y en su predicamento se incluían todas las obras anticatólicas fuesen de cualquier signo, aunque lo que más se temía era el espíritu de secularización que se vislumbraba como irrefrenable. Ante todo ello tenía que reaccionar el catolicismo de una forma inequívoca, combatiendo el liberalismo, haciendo presentes en todas las circunstancias las prohibiciones y condenaciones del Syllabus, apoyando la figura del papa y redoblando la vida de piedad. Los remedios más inmediatos se situaban en la avanzadilla integrada por un puñado escaso

(24) Cfr. L.R.C., 14-II-1897.

(25) Cfr. ibidem, 29-IX-1878, .La Iglesia y la libertad de imprenta.

(26) Cfr. ibidem, 9-1II-1879, -La propaganda antirreligiosa.. 
de intelectuales católicos entre quienes se destacaba al cardenal Zeferino González, al obispo Tomás Cámara, a los jesuitas Mendive, Fita y Mir y a los catedráticos Mateos Gago, Ortí y Lara y Menéndez Pelayo, sin olvidar al sacerdote e infatigable propagandista Sardá y Salvany. Como corolario se insistía en la educación católica para reorientar la perdida sociedad, poniendo un énfasis particular en el adoctrinamiento de la infancia y de la mujer a través de múltiples obras piadosas y de la presión sobre el estado para que, por medio de las leyes, se construyera una sociedad bajo los principios católicos ${ }^{27}$.

En medio del apogeo del sistema liberal se experimentaba una titánica lucha del catolicismo contra sus presupuestos ideológicos, incluso contra los que emanaban del denominado liberalismo moderado, que un sector nada despreciable de católicos pretendía hacer suyo. Entre las muchas argumentaciones en contra del liberalismo católico se esgrimía el que siempre se convertía en radical y por lo tanto equivaldría a una especie de herejía cuando se afirmaba que ([...] Si hay' Liberalismo no hay Catolicismo; y si hay Catolicismo, no hay Liberalismo [...]. Se subrayaba que el liberalismo contenía el error fundamental de negar o falsear el principio de autoridad, rechazando la autoridad divina de la religión y no sometiéndose a ella. Por otra parte, se destacaba el que los católico-liberales siguieran los mismos procedimientos que el jansenismo aunque negasen abiertamente el profesarlos. Tendríamos que hacer un alarde y afinar la metodología y la selección de fuentes empleadas en esta investigación sobre el tema para analizar la influencia del jansenismo en el endurecimiento ético y político de las posturas de la Iglesia decimonónica, con las evidentes repercusiones que ello ha tenido en su posterior desenvolvimiento ${ }^{28}$.

Una de las consecuencias más interesantes de esta polémica sobre la orientación política era la cuestión social, inmenso campo de batalla puesto que la Iglesia percibía el alejamiento de las masas trabajadoras. Este aspecto merece una atención aparte, pero no conviene olvidar que aún a finales de la centuria se contemplaba el tema con cierto optimismo ingenuo por parte del catolicismo, que procuraba presentar a los obreros la doble vía contradictoria del conformismo terrenal y de la tímida lucha por la consecución de mejoras materiales ${ }^{29}$.

Ante la amalgama de males políticos y sociales que aquejaban al mundo se ofrecía como única alternativa la religión y el catolicismo. León

(27) Cfr. ibidem, 15-I-1888, -La sociedad y la revolución. y 29-I-1888, .La sociedad moderna y la reacción católica.

(28) Cfr. ibidem, 3, 10, 17, 24 y 31-I-1897, .Cuestiones prácticas..

(29) Cfr. ibidem, 4-X-1898, .Las clases obreras. Intención general para el mes de setiembre de 1898. (Bendecida por el Papa). 
XIII era mostrado, en cuanto a imagen, como un ardiente defensor de los intereses de los obreros, para lo cual se aprovechaba la ocasión y se elaboraba un completo memorial de agravios del liberalismo y del socialismo en un alarde por superarlos

•[...] Alguno tal vez se atreverá a decir, como ha dicho recientemente un periódico, que el Papa ha hablado el lenguaje del socialismo.

Aunque mirándolo bien, en medio de todo, este último infeliz es el que lleva alguna mayor apariencia de razón. El Papa es ni más ni menos que un socialista. Ciertamente, pero un socialista cristiano, es decir, un socialista de la única sana y verdadera doctrina social [...]” ${ }^{30}$.

Se desembocaba así en que la Iglesia tenía las llaves para la solución de todos los problemas sociales, tal y como se desprendía de la obra de fray Cayetano de Igualada La Pacificación Social, presentada por la revista cual si se tratase de un manual de orientación sociopolítica, no exento de la consabidas condenaciones ${ }^{31}$.

Sorprenden algunas actitudes que se encaminaban a la instrumentación de las cuestiones sociales de cara a favorecer ciertas devociones, tanto en el plano humano como en el puramente espiritual. La forma en que se vulgarizó la imagen del papa León XIII y el enfoque social de sus doctrinas empujaba a una especie de culto personal adornado con aires casi mesiánicos. El pontífice era la pantalla para todo tipo de argumentos sociales y políticos, aún a sabiendas de que buena parte de la doctrina que se le adjudicaba no era ni siquiera admitida por la Iglesiaa pues la recepción que se hacía de las teorías elevadas a rango de doctrina pontificia era mediatizada por intereses e ignorancias particulares de los propagandistas de turno. En puridad, las doctrinas sociales de León XIII fueron difícilmente asumidas por los católicos españoles debido al enorme grado de compromiso que exigían en la acción social y, casi siempre se recurrió a la palabrería y al revisionismo de los textos del pontífice pero sin ponerlos en práctica. El otro modo de aprovechar interesadamente las cuestiones sociales consistió en fomentar devociones como la del Sagrado Corazón de Jesús, que se cifraba como la única solución a todos los problemas. En esto podemos ver cómo hasta en asuntos sociopolíticos se utilizó la fe de las mayorías, pues en el caso de la devoción al Sagrado Corazón se trataba de un momento en el auge de la misma ${ }^{32}$.

(30) Cfr. ibídem, 1-XII-1899, -León XII y la cuestión obreran.

(31) Cfr. ibidem, 28-XI y 12-XII-1886, .Situación actual del mundo. Su porvenir está en la

- Iglesia.

(32) Cfr. ibidem, 22, 29-IV y 6-V-1888, .León XIII es el papa providencial en el siglo XIX., 5 y 12-VII-1894, -La única solución de las cuestiones sociales. Intención general para el mes de agosto de 1894 . 


\section{3. La cuestión social y su trasfondo político. La condena del socialismo.}

Liberalismo y socialismo constituían para los publicistas católicos la antítesis de la doctrina de la Iglesia en materia política. El segundo era la consecuencia lógica del primero y ambos bebían del racionalismo revolucionario. Sin embargo no aparece claramente explicado el fondo materialista que los alentaba, motivo por el cual se perdía gran cantidad de energías en anatemas nada fáciles de entender. De otra parte, la simpleza con que se trataban algunas cuestiones ideológicas fundamentales daba noción de lo pobres que eran sus autores

"[...] El socialismo a su vez, pisando sobre las mismas huellas del liberalismo, camina por el mismo camino. Ya ha extendido largamente y sigue extendiendo sus doctrinas: ya ha organizado a sus secuaces en sociedad. Sintiéndose fuerte, grita, amenaza y espanta con las conjuraciones, con los asesinatos y con los regicidios [...]

Pero aún hay más. El liberalismo no sólo abre la puerta al socialismo, y dándoles entrada en la sociedad le pone en camino para llegar al principado, sino que también da principios y en grande escala a la demolición social, que el futuro soberano (el socialismo) debe llevar a término [...]*.

Se reitera que el liberalismo en el poder proclama la libertad de imprenta y de conciencia, dando lugar al excepticismo religioso, al ateismo individual y al ateismo social, apostillando que bajo el gobierno del liberalismo se destruye de hecho toda religión para sustituirla por la incredulidad del ateismo ${ }^{33}$.

En el balance social de Europa, que para la revista hacía Bautista Lázaro e Izquierdo a comienzos de 1880 , se pintaba el panorama con verdaderos tonos apocalípticos, sintetizándolo en las palabras de León XIII a los cardenales pronunciadas el día de navidad anterior

„[...] La Iglesia es fieramente combatida en sus doctrinas, en su autoridad, en su misión providencial en el mundo; la civil sociedad, arrancados de raíz los primeros fundamentos de todo orden, está minada por intestinas y profundas discordias, y por obra de personas malvadas y audaces está amenazada de total ruina [...] ${ }^{34}$.

Ante el avance del socialismo en Europa se percibía un innegable peligro social que era preciso conjurar a toda costa. Por supuesto que la solución propuesta era el catolicismo y nada más. No obstante, no debemos pensar en que la perspectiva descrita era fruto de la ignorancia en todos los casos, sino que en el de La Revista Católica se conocía la

(33) Cfr. ibidem, 23 y 30-III-1879, .Los demoledores del orden social.

(34) Cfr. ibídem, 11-I-1880, Balance social de Europa.. 
situación aproximada del socialismo europeo por medio de las publicaciones católicas extranjeras, principalmente La Civiltá Cattolica, que se detenía en largas descripciones de hechos y personajes significativos de la política europea ${ }^{35}$.

La reproducción de las conferencias y artículos del padre Félix Sardá y Salvany, director de la Revista Popular, era un punto de obligada referencia en el tratamiento del socialismo y de su antesala liberal. Los sucesos de La Mano Negra fueron hábilmente aprovechados por el publicista en una serie de conferencias que posteriormente vieron la luz como artículos en su revista, y reproducidos por su colega sevillana. Hoy puede parecernos demencial calificar aquella supuesta organización como un producto liberal, pero así lo hizo Sardá a muchos kilómetros del epicentro y con la información extraída del sensacionalismo de la prensa amparada en las fuentes policiales. Todo se confundía pues lo importante era no bajar la guardia y aprovechar hasta el más mínimo resquicio para herir de muerte al socialismo ${ }^{36}$.

En otra serie de conferencias de temática social arremetía Sardá contra el socialismo a la vez que definía los síntomas que lo hacían patente en la sociedad y hasta qué punto había calado la mentalidad socialista entre los sectores más populares.

-[...] Decíase años atrás: ¡Viene a marchas forzadas el Socialismo! Hoy esta frase debe ya retirarse por anticuada. Hoy debe decirse sencillamente: ¡El Socialismo está aquí! No es el trueno que se oye retumbar a lo lejos, es el rayo que hiende ya los aires y cruza con su eléctrico serpenteo nuestra atmósfera y hace crujir con su estridente estallido las bases del edificio social.

Hay tres señales mortales que pregonan que el Socialismo está aquí y que nos tiene ya tomadas casi todas las posiciones.

$1^{3}$ La que da él de sí mismo con esos frecuentes rugidos que atestiguan su ferocidad.

$2^{z}$ La que dan de él los actuales Gobiernos, que tienen admitida y como legalizada su existencia.

$3^{2}$ La que da de él la propia sociedad, que ya no se alarma por él, sino que le mira como huesped familiar. [...].

Ahí está otra voz más extendida aún que la del periodismo, pero que es eco de este, hija de este; hablo de la corriente popular, que en sus tres cuartas partes por lo menos se os declara francamente socialista.

(35) Cfr. ibidem, 10-IV y 18-III-1881, .Los peligros y los remedios del socialismo- y 5-XI-1882, -El socialismo en Europa.

(36) Cfr. ibúdem, 29-VII, 5, 12 y 19-VIII-1883, .La Mano Negra o polluelos de la última cría liberal. 
Apenas podeis, en efecto, asomaros a ciertos corrillos, o tomar el pulso a ciertas personas, o intimar confidencialmente con los hijos del pueblo, sin que os confiesen (muchas veces con extraño candor y con espantosa buena fe, si en tales materias caben buena fe y candor) que esperan un cambio de cosas que ha de dar por resultado una nueva organización social; cada una de estas bocas, pues; cada uno de estos niños y niñas (hasta niños y niñas, señores míos) no son sino voces con que os dice el Socialismo: ¡Aquí estoy! ¡Soy el Socialismo!. [...].

Y como prólogo de esta fraseología se permitía el sacerdote denominar al socialismo como la dinamita social, porque a juzgar por los más militantes el socialismo necesitaba destruirlo todo antes de transformar la sociedad ${ }^{37}$.

Poco antes de la promulgación de la Rerum novarum se recrudecieron las críticas hacia el socialismo en las columnas de la revista, propugnando los mismos y a la vez ingenuos remedios, e informando cumplidamente de cuantos adelantos hacía la causa socialista en los países occidentales ${ }^{38}$.

A raíz de la encíclica y dado su carácter social, se produjo un notable impacto temático que invitó a la revista a abordar dichas cuestiones con reiterada profusión. La encíclica pudo suponer en el área andaluza el punto culminante de la cuestión sociopolítica, aunque a partir de que se diluyeran sus efectos más inmediatos comenzó a bajar el tono de la polémica en la revista ${ }^{39}$.

El mismo Tercer Congreso Católico Nacional, celebrado en Sevilla en 1892, se hizo eco de la cuestión social, como vimos, de una forma amplia aunque tímida porque eran muchas las prevenciones ante el tratamiento público de cuestiones tan vitales y controvertidas ${ }^{40}$.

\section{4. El credo político de los católicos y el adoctrinamiento.}

El director de La Revista Católica, Ventura Camacho, no ocultaba en 1878 las estrechas vinculaciones que cabía ver entre la religión y la política, sobre todo desde el triunfo ideológico del racionalismo, y ade-

(37) Cfr. ibidem, 19 y 26-IV, 3, 10, 17, 24 y 31-V-1885, .La dinamita social. Cuatro conferencias del pbro. D. Félix Sardá y Salvany. y 13-X-1886, .El socialismo y el jubileo sacerdotal del Papa León XiIr.

(38) Cfr. ibídem, 20 y 27-IV-1890, -El socialismo contemporáneo y 4 y 18-V y 1-VI-1890, •De los remedios para el socialismo.

(39) Sobre la encíclica y la cuestión social, vid. ibidem, 7 y 21-VI, 3-VII-1891 y 21-II-1892. Una apreciación detallada sobre el tema en DOMINGUEZ LEON, J., La doctrina social... y La Rerum novarum....

(40) Cfr. DOMINGUEZ LEON, J., La Rerum novarum.... 
más no se recataba de expresar que quienes deseaban separarlas perseguían como fín dominar a los pueblos para explotarlos a su capricho

‘[...] Es, pues, un verdadero sofisma, y además una utopía, el principio de que la religión debe estar separada de la política; antes, al contrario, la política y la religión deben caminar de acuerdo, para conseguir la felicidad temporal posible y la espiritual de los asociados, y lejos de deberse encerrar los sacerdotes dentro del santuario, tienen obligación estrecha de andar entre el pueblo y de ejercer en medio de este su saludable y eficaz influencia [...]

No hay, repetimos, un hecho político que no lleve en pos un hecho religiosos, y al contrario; y teniendo la Iglesia, no sólo derecho, sino obligación indeclinable de intervenir en todo asunto religioso, la lógica persuade que por precisión debe intervenir en aquellos actos políticos intimamente ligados a los otros [...]. ${ }^{41}$.

Pero en esa dinámica era absolutamente imprescindible lograr una eficaz movilización de los católicos, motivo por el cual se generaliza un soterrado llamamiento a los laicos cuando tradicionalmente se les había mantenido separados de ciertas acciones. El signo de los tiempos había cambiado tanto que ya no era posible una defensa de los dogmas y la posición de la Iglesia sin la intervención decidida del laicado. Se hacía referencia expresa de que la jerga liberalesca había convertido el concepto de católico en el de clerical, pero no por casualidad, sino para. aprovecharse del momento de postración por el que atravesaban el clero y la jerarquía en su conjunto con respecto a los poderes políticos y económicos. Como conclusión era preciso desligar lo que se entendía. como actividades propias de los laicos en la perspectiva de la acción social general de toda la Iglesia ${ }^{42}$.

Fuera de la Iglesia y de sus dictados y normas se planteaba que no era posible encontrar sino nihilismo y anarquía como consecuencia de la irreligión, y ante ello era imprescindible proponer un ideario de aplicación en política, con normas claras y precisas para todos los católicos. $L a$ Revista Católica lo encontró a la justa medida en lo elaborado por Ortí y Lara, cuyos rasgos más significativos consistían en: la sociedad natural es anterior a la política; rechazo del matrimonio civil; la sociedad civil ha sido ordenada por la divina providencia; auxilio mutuo y asociación en la sociedad y su extensión a las naciones; necesidad de una autoridad; rechazo del absolutismo y de las formas democráticas de gobierno, en especial las de soberanía popular; oposición a las libertades políticas y de conciencia. Su coherencia está sentada pero su claridad de cara a la

(41) Cfr. L.R.C., 7-VII-1878, sLa religión y la política.

(42) Cfr. ibídem, 30-VI y 6-VIII-1882, Misión de los seglares católicos en la época moderna. 
mayoría de los católicos era ciertamente utópica. Con todo, probablemente fuera la primera vulgarización sintética de esta naturaleza en el catolicismo español del momento ${ }^{43}$.

El adoctrinamiento se llevó a efecto de manera sutil a través de folletines concebidos a manera de diálogos entre dos o más personajes, uno que hacía de adoctrinador y otro que recibía las enseñanzas, inspirándose en la más pura versión catequética de responder a preguntas previamente suscitadas. Alguna de estas cortas teologías morales salió incluso de la pluma de Sardá, por lo que cabe pensar que tuvieron gran difusión en la prensa católica de la época ${ }^{44}$.

Un último punto cabría dedicarlo al aprovechamiento por la jerarquía de las adversidades políticas, de lo que tenemos un fiel ejemplo en la dialéctica desplegasa en torno al problema colonial en 1898, primero bendiciendo la guerra contra Estados Unidos calificada de justa, y más tarde señalando que la pérdida y el desastre se podían considerar como una especie de castigo del cielo por las desviaciones políticas de los españoles. Era otra forma de adoctrinar coyunturalmente ${ }^{45}$.

(43) Cfr. ibídem, 9, 16 y 23-XI-1884, .Irreligión, nihilismo y anarquían y 30-X-1887, El credo político de los católicos.

(44) Cfr. ibídem, 26-IV, 10-V, 14 y 21-VI, 19 y 26-VII, 2-VIII-1891, :La cuestión social. y 30-V, $6,13,20$ y $27-V I-1897$, .Cristo y los obreros.

(45) Cfr. ibidem, 22-V-1898, . Circular del Excmo. Sr. arzobispo de Sevilla para que se hagan solemnes rogativas en favor de la nación española. y 19, 26-VI, 3, 10, 17, 24 y 31-VII1898 , -La religión y la guerra o españoles y yankees. 